\title{
REVALORIZACIÓN DEL MOVIMIENTO ANTI-MANICOMIAL DE FRANCO BASAGLIA
}

\author{
Leonardo Montecchi ${ }^{1}$
}

La trayectoria vital de Franco Basaglia se entrecruza con el movimiento de los años 60/70 en Italia y en el mundo. Si hoy pensamos en las formas de aquel movimiento debemos, en primer lugar, ubicarnos para dar cuenta del punto de vista desde el cual provienen nuestras observaciones.

Estamos, o por lo menos yo estoy, sobre naves irregulares, corsarias quizás, que atraviesan un plano de consistencia caracterizado por la circulación de mercaderías pero no de sujetos; y nos ponemos, o me pongo, como nudo de la red, punto de encuentro y reclutamiento para defender y ampliar este espacio libre en el cual los sujetos, para circular, no deben trasformarse en mercancías. De hecho, si no se es mercancía, fuerza de trabajo requerida, podemos ser capturados y encerrados en lugares ad hoc llamados centros de detención temporal, que no son otra cosa sino campos de internación, sólo porque no estamos donde somos requeridos como mercancía, o donde un poder cualquiera dice que no deberíamos estar: somos clandestinos. La condición humana de estar en un lugar donde para alguien no deberíamos estar, deviene privada de derecho: el sujeto no es titular de habeas corpus, es, como dice Giorgio Agamben, una vida desnuda y sobre su cuerpo se ejerce el control bio-político.

En este mundo hay pocos opositores a la constitución de los dispositivos totalitarios de control, dispositivos que se constituyen en todas partes y que privan de derecho a los sujetos. Por ejemplo, en el mundo

Director del Instituto de Prevención “José Bleger”, Rimini, Italia. 
del trabajo los instrumentos contractuales siempre son más "flexibles", es decir, parcelados, individualizados: la contratación colectiva es combatida fuertemente en nombre de la ideología individualista que despedaza y fragmenta la fuerza de la clase destruyéndole la conciencia colectiva.

La lucha de clase ha tomado nuevas formas porque la clase obrera ha sido vencida e incluso ha perdido la conciencia de ser, ya no está presente y no se sabe donde esté.

La oposición social se presenta bajo formas de rebelión que raramente superan el horizonte de una cuestión singular. En Italia, por ejemplo, está el problema de la basura en Nápoles, el túnel en el valle de Susa en Piemonte para el tren de alta velocidad, la oposición a la ampliación de la base de la OTAN en Vicenza. Pero es muy difícil la reunificación de todos estos "frentes de lucha" alrededor de una perspectiva común de cambio.

En síntesis, ha habido un cambio en la forma de producción capitalista. Ya vivimos en una era que ve el dominio de la producción inmaterial; es decir, la mercancía producida no vale -como justamente decía Marx- por el lado del uso, por su componente material, sino por el lado del intercambio, o sea, por su componente inmaterial.

Hemos alcanzado un nivel productivo en el cual el fetichismo de la mercancía expresa su dominio sobre el planeta mediante un verdadero sex appeal de lo inorgánico, como decía Walter Benjamín.

Esto significa que no se produce tanto la cosa como el modo de consumirla; y el modo de consumirla determina una costumbre: un hábito, como diría Pierce. Para decirlo brevemente, la producción actual produce el consumidor, su subjetividad, o si queremos, su conciencia, o mejor, su falsa conciencia, nos habría dicho Lukács.

Es así como nos encontramos ante un aparato productivo que se despliega en varios planos, quizás en mil planos, de los cuales hablan Deleuze y Guattari, y que se nos presenta como una máquina, es decir un aparato compuesto de partes biológicas y mecánicas que incesantemente producen modos de atribución de significados a significantes, o sea, los maquinistas contemporáneos producen ideología en forma incesante. De esto W. Reich nos mostró la "fuerza material". 
Esta es la época del semio-capitalismo, una época en la cual las varias provincias de significado, por decirlo a la manera de Schutz, se reunifican bajo la égida de una forma que busca mantener unidas las distintas semióticas particulares; la producción de signos y significados determina los hábitos de comportamiento y, por lo tanto, las relaciones sociales contemporáneas.

Habla más de nosotros una novela de Philip Dick que un tratado de sociología académica. Esta organización social contemporánea está produciendo, ha producido, una mutación antropológica.

Ante todo pensemos en el tiempo y en el ritmo del vivir. Desde que la población de la ciudad del mundo ha superado a la de los campos, hemos entrado en un punto de no retorno. El equilibrio del planeta se ha roto definitivamente a favor de las zonas urbanas, los recursos mundiales son monopolizados y distribuidos para mantener los desequilibrios, la forma de la megalo-poli es cada vez más caótica, impredecible y dominada por los slum ${ }^{2}$. La vida en el slum, como lo demuestra Mike Davis, es el paradigma de la vida contemporánea.

El slum no es sólo Delhi, es Los Angeles. Las ciudades ya no están organizadas según la lógica de: centro, periferia, barrios residenciales, barrios populares de obreros, sino según recintos y barreras que distinguen estilos de vida, mundos paralelos que no debieran encontrarse, planos y niveles de metrópolis tipo la de Los Angeles de Blade Runner.

A causa de esto tenemos zonas libres de prostitución, barrios con luces rojas, pequeñas aldeas turísticas -donde debería vivirse la vida del Truman Show- rodeadas de muros más allá de los cuales viven en reserva seres deprivados que hay que controlar por peligrosos, violentos sin motivo y, por lo tanto, aptos todos para ser encerrados en la cárcel, como lo ha demostrado Loic Wacquant. De nuevo estamos ante una situación de "gran internación" como en el inicio de la era moderna, analizada por Foucault, cuando los vagabundos, los irregulares, los no "burgueses" (que eran los habitantes del burgo a los cuales se oponían los villanos o campesinos y los vagabundos) debían ser controlados y encerrados por ser considerados peligrosos para la propiedad del nuevo orden social de la burguesía naciente.

2 Slum podría ser traducido como condominio (nota del traductor). 
Y de nuevo vuelven los espacios que la bio-política ha preparado para controlar y disciplinar los cuerpos, que encuentran justificaciones "científicas" para abolir el habeas corpus e impedir la libre circulación, se trata de una aplicación en amplia escala del reduccionismo biológico.

Aún en los años 70 del siglo pasado comenzó la ofensiva del neoliberalismo y del reduccionismo con el Manhattan Institute y con libros tales como The Bell Curve Intelligence and Class Structures in American Life, de Richard Hernstein y Charles Murray, en el cual se sostiene que en los Estados Unidos las desigualdades raciales y de clase reflejarían diferencias individuales de "capacidades cognitivas". En este texto se sostiene que: "Muchos piensan que los criminales provienen de los barrios de mala fama de la ciudad. Desde cierto punto de vista tienen razón, puesto que justamente en esos barrios es donde residen en gran medida las personas de baja capacidad cognitiva”.

Para estos autores se deviene criminales, no por causa de las privaciones materiales (deprivado) características de una sociedad desigual, sino por carencias mentales y morales (depravado). Con estos principios se vuelve a introducir la idea de que existen personas "peligrosas" en sí, por bajo cociente cognitivo, en este caso, ya no por características raciales, como decían de los nor-africanos los psiquiatras franceses de los años 50, duramente criticados por Franz Fanon. Este decía que se hacía de la agresividad una característica principal de una etnia y no se atribuía aquella al efecto del colonialismo.

Así, los autores de The Bell curve ligan la agresividad y la peligrosidad social al bajo cociente cognitivo, y no relacionan este cociente con características sociales, con el acceso a la instrucción y así sucesivamente...

Estas teorías han llevado a un aumento importante de los reclusos en las cárceles de los EEUU. Pero la gran internación contemporánea no está sólo en las cárceles y en los centros de identificación y detención temporales para inmigrantes, han surgido verdaderos campos de concentración como Guantánamo, donde no existe ninguna garantía de ningún tipo para las personas encerradas allí.

Por lo tanto, estamos en presencia de una nueva organización del espacio en el planeta, con la reducción, hasta la desaparición, de las zonas 
vírgenes. Una mutación en la relación entre ciudad y campo a favor de la ciudad que deviene cada vez más megalo-polis, y una estratificación progresiva de los espacios urbanos en niveles diferenciados que concretizan el miedo al otro en su intento por controlar cualquier comportamiento que se "desvía" con la bio-tecnología: sistema de tele-cámaras omnipresentes, exámenes de $\mathrm{ADN}$ selectivos, bancos de datos de cualquier tipo, controles de las comunicaciones telefónicas y así sucesivamente.

El aumento de la velocidad de transporte y telecomunicación, tal como lo mostró Virilio, ha provocado además una ulterior mutación de las costumbres de la vida cotidiana, traslados individuales y de masa de una ciudad a otra, de un país a otro, de un continente a otro, han realizado una mezcla de hábitos de vida, comportamientos, creencias religiosas, que no tiene comparación con ninguna era pasada. Los vínculos sociales de tipo comunitario se han debilitado, las comunidades entendidas como islas o provincias de significados han desaparecido. Los mismos estados nacionales se presentan como barreras anacrónicas de resistencia al flujo cada vez más veloz de comunicación real y virtual y a la circulación de los cuerpos y de las informaciones. Esta situación de cambio se acompaña de ansiedad, tal como lo ha demostrado Pichon-Rivière; el cambio produce antes que nada una ansiedad depresiva, el miedo a perder las seguridades adquiridas, el miedo a perder la presencia, si usamos el lenguaje de Ernesto De Martino, cuando extiende al análisis de las “apocalipsis culturales" su investigación sobre la crisis de la muerte y sobre el duelo.

A este miedo se puede reaccionar con una ansiedad confusional, una pérdida de los límites de la identidad que fácilmente encontramos en algunos emigrantes, pero también en muchos habitantes de las metrópolis que están implicados en estos procesos de cambio.

Es un estado de sufrimiento psíquico que no puede ser negado. Es importante aquí la lección de Franco Basaglia que no nos dijo nunca que la enfermedad mental no existía, nos decía que la nosografía psiquiátrica era una superestructura ideológica, nos decía que la categorización del sufrimiento era una cosificación que producía como efecto la reducción del sujeto a la exclusiva definición diagnóstica, nos decía que el manicomio, en cuanto institución, no era tan sólo el edificio en el cual estaban contenidos 
los locos, sino que constituía el dispositivo ideológico que lo hacía posible, y en consecuencia estaba referido a todo el aparato nosográfico catalogador y provocador de distancia que producía la enfermedad que decía curar.

Pero Basaglia nunca nos dijo que no existía el sufrimiento psíquico, nos dijo en cambio que la psiquiatría manicomial con vocación de custodia se ponía de parte del control social y negaba el aspecto terapéutico, la cura del sufrimiento del otro...y que nuestra tarea era la negación de la institución mancomial mediante el análisis de nuestro mandato social, el rechazo a un mandato social de custodia y la aceptación de uno terapéutico. Esto significa que nuestra ideología, sí, porque nosotros tenemos una ideología, es la que está sintetizada sobre un muro del manicomio de Trieste: la libertad es terapéutica. Esta idea se contrapone totalmente a la idea del control que se está expandiendo en nuestro planeta, es una idea que sigue diciéndonos do not panic, nada de miedo.

En medio de esta confusión, nosotros entramos por el lado de quien construye instrumentos para pensar, para fabricar conceptos, una vez más Deleuze y Guattari, que definen la actividad filosófica como la fabricación de conceptos, pero también Antonio Gramsci, quien nos enseñó a trabajar con el sentido común y nos ha dicho que el sentido común es la estrategia para aquella reforma intelectual y moral que, según él decía, era necesaria no sólo en Italia sino en el mundo entero.

$\mathrm{Al}$ contrario, existen industriales del miedo que difunden a través de los media mainstream la peste psíquica de reichiana memoria. Esta peste no es otra cosa sino la elaboración paranoica del luto, como decía Franco Fornari cuando analizó los movimientos inconscientes de la guerra. También para Pichon-Rivière la ansiedad paranoide es una reacción ante el cambio, es una de las resistencias más potentes. Un peligro se detecta en la novedad, en la situación nueva: lo extranjero, lo desconocido, es potencialmente peligroso y, por lo tanto, se aprestan sistemas de defensa para disminuir la supuesta peligrosidad: ejército en las calles, control en los campos nómades, toma de huellas a los niños rom, para que de este modo los "ciudadanos" puedan sentirse más seguros. Estas son algunas acciones del nuevo gobierno italiano de derecha, débilmente contrastadas por una oposición evanescente. Pero acciones análogas ocurren por doquier en el resto del planeta. 
Se trata de la creación continua e incesante de muros, muros que quisieran defender y separar y alejar al otro, el peligroso, el enemigo. El prototipo de estos muros son los muros del manicomio que Franco Basaglia echó abajo en Italia. Pero Armando Bauleo siempre nos lo ha recordado, también existen los manicomios mentales en los cuales se apoya la resistencia al cambio.

La resistencia al cambio se atrinchera sobre el bastión de la identidad, todos tienen miedo a confundirse, a perder su identidad, es por esto que hay un llamado constante a la identidad de etnia, de religión, de comunidad, etc., y entonces se construyen de muros y murallas para estriar y controlar el espacio liso de la multitud nómade.

Amartya Sen ha demostrado muy bien cómo este llamado a la identidad de lo idéntico se acompaña de violencia en contra del otro que no es yo. Este otro es peligroso y amenazante: no es yo, y en este universo paranoico todo lo que no es yo es enemigo y debe ser aniquilado. Es este el vocabulario usado actualmente por los militares en guerra: janiquila!

Nosotros trabajamos sobre otro, contrastamos la obsesión de la identidad porque creemos que el otro es constitutivo del yo, porque sabemos que no puede haber un yo sin otro. Estamos con Rimbaud: yo es otro.

Es por eso que en este Aniversario 30 de la Ley 180, o Ley Basaglia, debemos lanzar una contraofensiva a la ideología dominante de la psiquiatría nosográfica clasificatoria del DSM. Esta es la ideología que permite el control y la contención de los comportamientos de las muchedumbres emigrantes de parte de funcionarios que, por medio de test, aplican diagnósticos estigmatizadores que transforman a sujetos confusos y sufrientes de identidad múltiple en individuos de una sola dimensión, como diría Marcuse, la dimensión psicopatológica. Nosotros también somos los replicantes de Blade Runner sometidos al test para ser descubiertos, pero también somos los funcionarios que pasan el test a otros.

Es justamente Franco Basaglia quien nos enseñó a interrogarnos sobre lo que hacemos, él, que tenía coincidencias con Sartre, sabía que cada uno de nosotros no es un psiquiatra sino que hace de psiquiatra, por lo cual debe interrogarse acerca de lo que está haciendo, puesto que su ser no se agota con su hacer. Y, por lo tanto, así como el bordeline es multitud y no 
solo borderline, también el psiquiatra que lo diagnostica es multitud. Por esta razón el análisis del mandato social es para nosotros-psiquiatras basaglianos- ineludible. Franco Basaglia, con el descubrimiento qué se podía y se debía hacer del análisis del propio mandato social, extrayendo de él las consecuencias, nos condenó. No podemos fingir que no se puede hacer, es como cuando el Dr. Sommelweis descubrió que la fiebre puerperal era ocasionada por los cirujanos que no se lavaban las manos. Se necesitó mucho tiempo y muchas batallas para que este descubrimiento fuese de sentido común, pero aquel que lo sabía no podía ser causante de sufrimiento y muerte incluso si iba en contra de las leyes y disposiciones de la época.

Así, el descubrimiento que el manicomio es una institución total que produce la enfermedad que pretende curar nos impulsa a una batalla abolicionista, y tomar conciencia que la abolición de la libertad que se efectúa en cualquier institución total es fuente de sufrimiento y muerte, extiende este movimiento a una visión más amplia, hacia un auto-gobierno de las multitudes deseantes que habitan esta contemporaneidad y que quieren vivirla fuera de cualquier control paranoico, porque sienten como tarea común -como diría Armando Bauleo- la construcción de una comunidad a advenir.

Texto traducido por Marcella Chiarappa

Ponencia presentada en la Jornada "A treinta años de la Ley antimanicomial en Italia", realizada en la Facultad de Ciencias Sociales de la Universidad de Chile el 30 de agosto de 2008 . 